\title{
Spontaneous ventral urethral fistula in a young man whose mother had a retained IUD in uterus during the gestation
}

\author{
Shuyi Wei, MD; Qiang Li, MD; Senkai Li, MD; Chuande Zhou, MD; Fengyong Li, MD; Yu Zhou, MD; \\ Jian Ding, MD; Yujiao Cao, MD; Siya Zhan, MD; Linhai Xie, MD
}

10th Department, Plastic Surgery Hospital, Chinese Academy of Medical Sciences and Peking Union Medical College, Shi-ling-Shan District, Beiinng, PR China

Cite as: Can Urol Assoc J 2014;8(1-2):e92-5. http://dx.doi.org/10.5489/cuaj.1551

Published online February 12, 2014.

\section{Abstract}

Urethral fistula is rare and is usually a complication of penile and urethral surgery. A few congenital cases have been reported. To our knowledge, there are only 2 reports about spontaneous ventral urethral fistula in the English literature. We present what we believe is the first case of a patient with spontaneous ventral urethral fistula whose mother had a retained IUD in uterus during the gestation.

\section{Introduction}

Urethral fistula is rare and usually a result of infectious complications, trauma or surgery. ${ }^{1}$ Isolated congenital anterior urethrocutaneous fistula is extremely rare and few cases have been reported..$^{2,3}$ One report in a severely infected young man due to poorly controlled diabetes and the second report in a healthy man with unknown etiology. ${ }^{4,5} \mathrm{We}$ present the first case of a spontaneous ventral urethral fistula in a young man with suspicious origin: his mother had a retained intrauterine device in uterus during the gestation.

\section{Case report}

A 26-year-old male was referred to our department due to an additional opening on the ventral side of the penis. According to his mother, when he was born there was an area in the distal ventral part of the penile shaft in which the skin was nearly transparent. When he was 2 years old, the thin skin spontaneously ruptured without any visible reason. At first, the ruptured hole was like a pinpoint and the urine dropped from the hole when voiding, however, without any treatment it turned into a bigger hole and the urine voided completely from the hole. The patient denied a history of surgery (e.g., hypospadias repair, circumcision), trauma, stone impaction, or strangulation. He did not see a doctor before because he was still able to urinate standing up; however, his misdirected semen during ejaculation and his concern over infertility led him to the hospital.

Physical examination revealed bilateral normally positioned testes, normal glans and frenum of prepuce (Fig. 1), a normal external urethral meatus and an additional opening on the ventral aspect of the penile shaft $\left(2.0 \mathrm{~cm} \times 2.5 \mathrm{~cm}^{2}\right.$ (Fig. 2). A No.5.5 urethral probe was passed through the fistula (Fig. 3), which came out of the glandular meatus suggesting an intact distal urethra. All the routine investigations were normal. The karyotype analysis and WT1 gene examination ${ }^{6}$ were normal (Fig. 4). The patient received fistula repair surgery and during the operation, no chordee was observed when the penis was erect (Fig. 5). Fifteen days after the surgery, the patient was able to void normally. There was no recurrence at the 7-month follow-up period (Fig. 6).

The patient's mother denied any family history of disease; she did say that during her gestation she had an intrauterine device (IUD) inserted into her uterus by the family planning department when she was 24 (she had already given birth to 1 boy and 1 girl). Seven days later, the IUD was washed out by the menstrual blood and she found it on the sanitary towel which appeared as a metal single ring. Forty days later, a new IUD was inserted into her uterus immediately after an artificial abortion. A month after this, she became pregnant, although she was unaware of this until she felt fetal movement 5 months into the pregnancy. She did not receive any prenatal treatment and no actions were taken about the IUD in her uterus. She delivered the boy (our patient) 20 days post-term and found that the IUD was attached to the embryonic membrane.

\section{Discussion}

It seems plausible to conclude that the patient was born with congenital defect of hypoplasia of corpus spongiosum, according to the medical history of the transparent part of the skin at birth and the outcome of the spontaneous urethral 


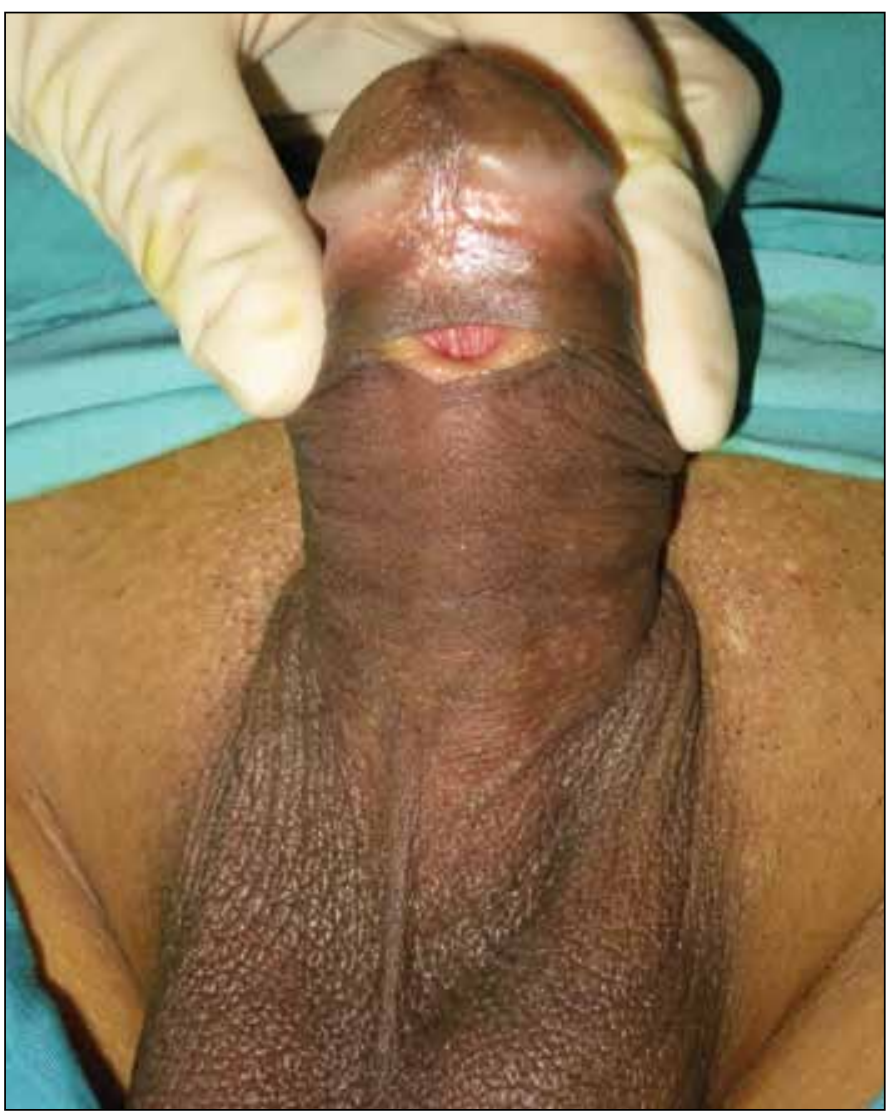

Fig. 1. Frenum of prepuce exists.

fistula when he was 2 years old. Unquestionably, the spontaneous ventral urethral fistula originated from the congenital hypoplasia of corpus spongiosum. Therefore, to investigate the etiology of the spontaneous ventral urethral fistula, we had to figure out the pathogenesis of the congenital hypoplasia of corpus spongiosum.

There are 2 general causes fetal anomaly: genetic and environmental factors. ${ }^{6}$ However, in our patient, the karyotype and WT1 gene analyses were normal, which ruled out any potential genetic factor at play. Therefore, environmental factors were paramount in the patient's congenital deformity pathogenesis. In light of the risk factor during the pregnancy and the fact that the patient was born with congenital hypoplasia of corpus spongiosum, we speculate that the IUD in the mother's uterus might be related to the birth defect and ultimately to the spontaneous ventral urethral fistula.

Based on the single ring shape and the date, we speculated that the IUD in the mother's uterus was a stainless steel ring (SSR) without Cu or hormone (a device that is very inexpensive and ineffective, yet is used widely by the family planning department in China). ${ }^{7}$ Ganer and colleagues proposed that women conceiving with an IUD without early removal are at increased risk of fetal urogenital malformations, but no explanations were given for the pathogenesis. ${ }^{8}$ Cook and Stephens proposed that a mechanism for the con-

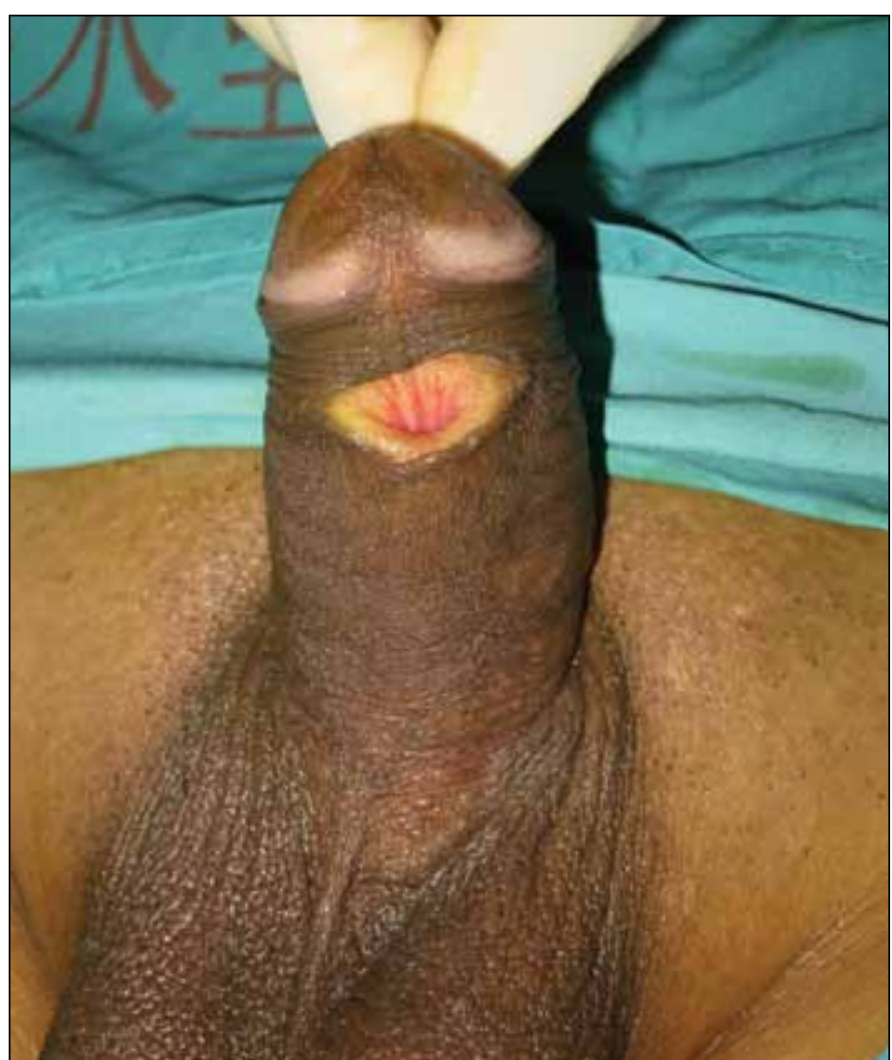

Fig 2. The location and size of spontaneous ventral urethral fistula.

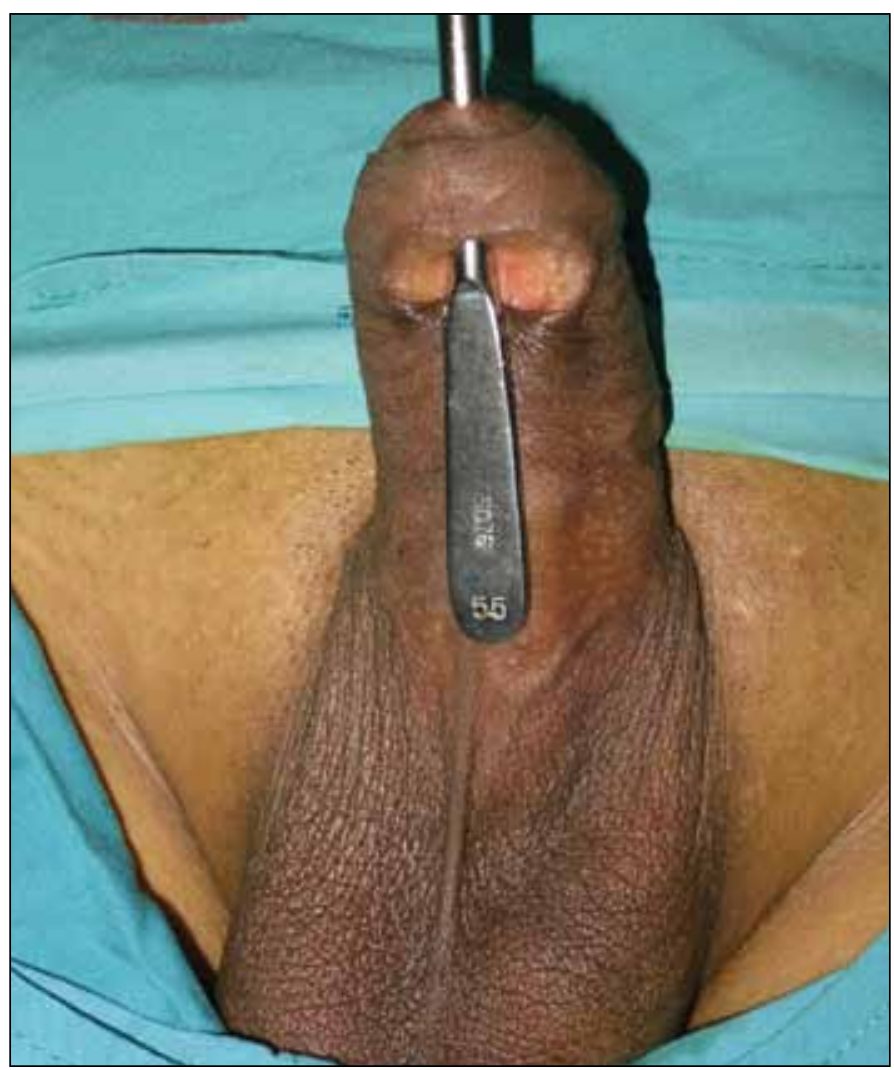

Fig 3. The No.5.5 urethral probe can go through the distal urethra smoothly. 
Wei et al.

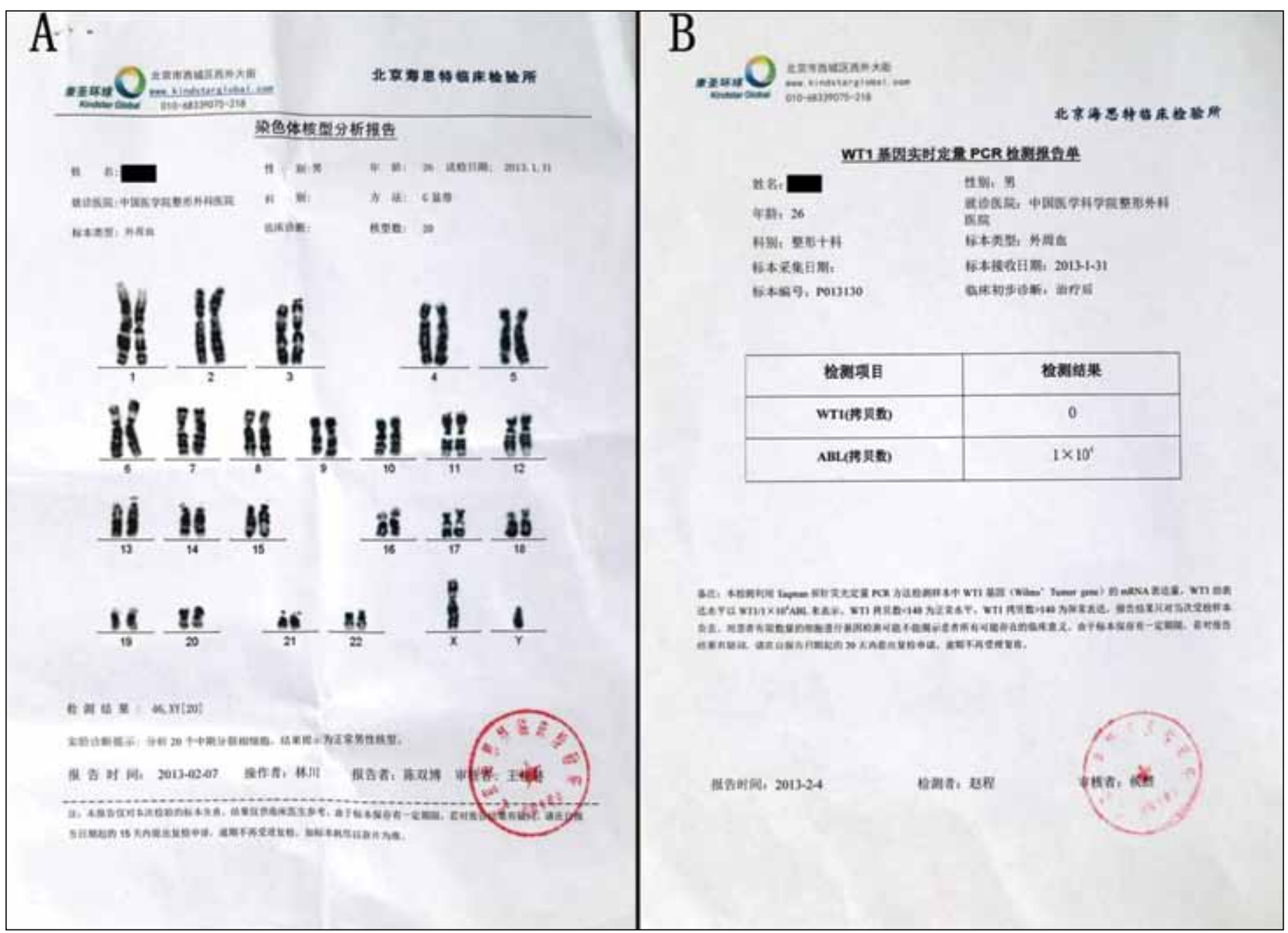

Fig. 4. The karyotype analysis and WT1 gene examination are both normal.

genital urethral fistula may be that the pressure atrophy from the heel of the baby's feet, leading to pressure necrosis. ${ }^{9}$ Both propositions have led us to believe that the occurrence of the birth defect in our patient might be relevant in light of the hypothesis of the male urethra development. ${ }^{10}$ When the fetus was small and the uterus had a relatively bigger space, there was presumably little contact between the SSR and the fetus. Therefore, the urethra and the prepuce could develop normally. However, as the fetus grew, the uterus had a relatively smaller space, which caused the SSR to attach itself to the fetus. When the urethra and prepuce matured and frenum existed, the mesenchymal tissue surrounding the urethra proliferated and formed the corpus spongiosum in the normal condition. ${ }^{10}$ Due to the attachment of the SSR to the fetus' sinus urogenital and the mechanical stimulus or pressure of the SSR, the corpus spongiosum failed to form in the local region. Consequently, the patient was born with congenital hypoplasia of corpus spongiosum; this means that the transparent area was composed of only urethra and prepuce without spongiosum. Eventually, this area was not able to bear the strikes of the urine flow, which caused the spontaneous rupture when he was 2 . This finally formed the spontaneous ventral urethral fistula.

\section{Conclusion}

The treatment of spontaneous urethral fistula is not difficult. Our case with its unique medical history opens an interesting and extensive discussion on the possible correlations between spontaneous ventral urethral fistula, congenital hypoplasia of corpus spongiosum and conception with a retained IUD. Our hope is that our case can promote further research on male urogenital differentiation and development.

Competing interests: Dr. Dr. Wei, Dr. Q. Li, Dr. S. Li, Dr. C. Zhou, Dr. F. Li, Dr. Y. Zhou, Dr. Ding, Dr. Cao, Dr. Zhan and Dr. Xie all declare no competing financial or personal interests.

This paper has been peer-reviewed. 


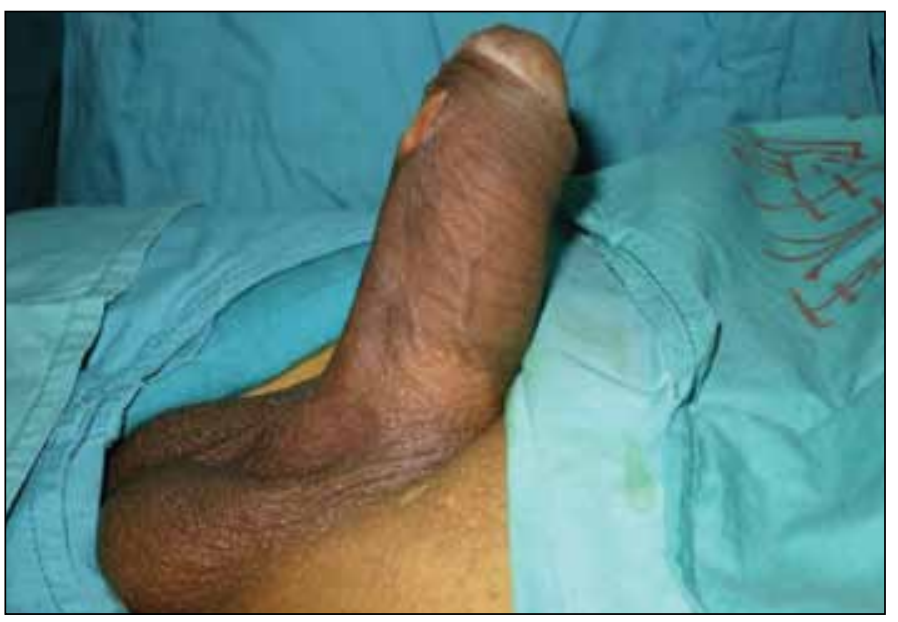

Fig. 5. No chordee when erecting.

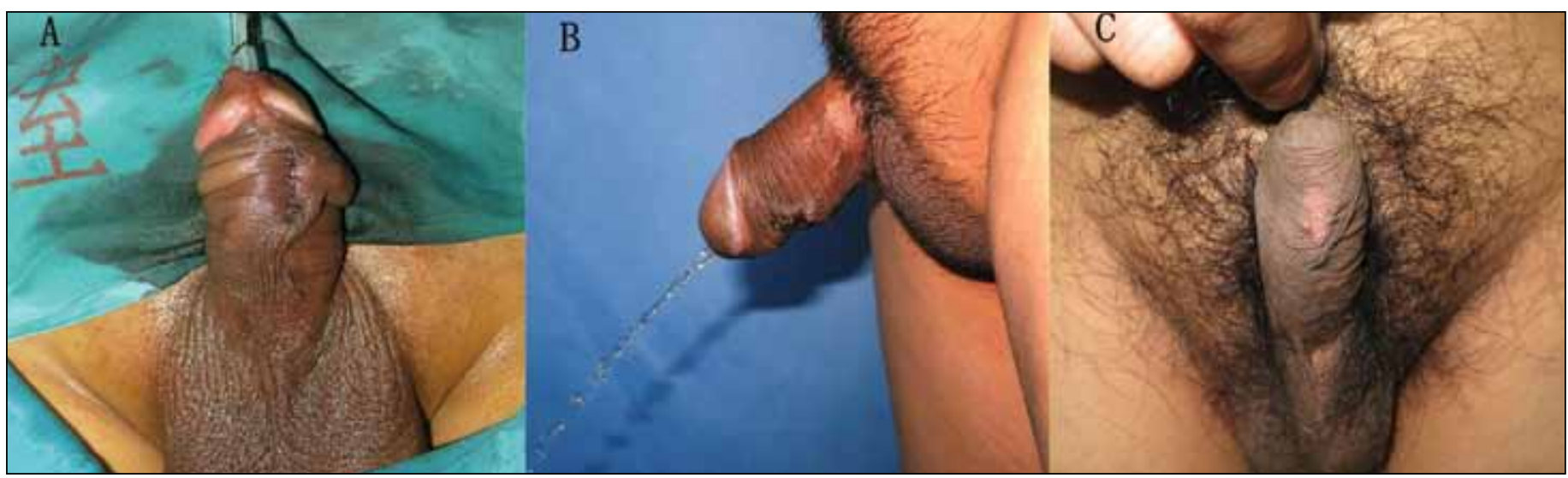

Fig. 6. A: The ventral surface of the penis after immediately surgical correction B: The patient voided normally 15 days after the surgery C: The wound was basically healed up 4 months after the surgery.

\section{References}

1. Lau JT, Ong GB. Subglandular urethral fistula following circumcision: Repair by the advancement method. J Urol 1981;126:702-3.

2. Chen $Q$, Xiao WL, Jiang $Y M$, et al. Adult isolated congenital anterior urethrocutaneous fistula. Urol Int 2011;86:361-4. http://dx.doi.org/10.1159/000321920

3. Yavuz Akman R, Cam K, Akyuz 0, et al. Isolated congenital urethrocutaneous fistula. Int I Urol 2005;12:417-8. http://dx.doi.org/10.1111/i.1442-2042.2005.01050.x

4. Denzinger $S$, Wieland WF, Burger $M$, et al. Spontaneous ventral urethral fistula in a young diabetic man: a case report. J Med Case Rep 2007;1:80. http://dx.doi.org/10.1186/1752-1947--1-80

5. Akkoc A, Metin A. Spontaneous ventral urethral fistula in a young healty man and a modified surgical technique of urethral fistula repair. Can Urol Assoc J 2012;6:280-2.

6. Kalfa N, Philibert P, Baskin LS, et al. Hypospadias: Interactions between environment and genetics. Mol Cell Endocrinol 2011;335:89-95. http://dx.doi.org/10.1016/i.mce.2011.01.006
7. Cheung VYT. A 10-year experience in removing Chinese intrauterine devices. Int I Gynecol Obstet 2010;109:219-22. http://dx.doi.org/10.1016/i.iigo.2009.12.018

8. Ganer $\mathrm{H}$, Levy A, Ohel I, et al. Pregnancy outcome in women with an intrauterine contraceptive device. Am J Obstet Gynecol 2009:381:1-5.

9. Cook WA, Stephens FS. Pathoembryology of the urinary Tract in Urological Surgery in Neonates and Young Infants. LR King, ed., Saunders, Philadelphia: PA; 1988.

10. Kurzrock EA, Baskin LS, Cunha GR. Ontogeny of the male urethra: Theory of endodermal differentiation. Differentiation 1999;64:115-22. http://dx.doi.org/10.1046/i.1432-0436.1999.6420115.x

Correspondence: Dr. Qiang Li, 10th Department, Plastic Surgery Hospital, Chinese Academy of Medical Sciences and Peking Union Medical College, No.33 Ba-Da-Chu Road, Shi-Jing-Shan District, Beijing 100144, PR China; liqiang20120813@126.com 